\title{
0 mínimo existencial ecológico e os ditames salutares da Educação Ambiental
}

\author{
Raquel Torres de Brito Silva*®, Clara Angélica Gonçalves Cavalcanti Dias® \\ Programa de Pós-Graduação em Direito, Universidade Federal de Sergipe, São Cristóvão, 49100-000, Sergipe, Brasil. \\ *raqueltorres.95@hotmail.com
}

Recebido: 24 setembro 2019 / Aceito: 15 novembro 2019 / Publicado online: 25 maio 2020

\begin{abstract}
Resumo
Com um destaque preliminar acerca da importante evolução histórica do Estado de direito até o hodierno cenário do Estado Democrático e Socioambiental, fruto do Constitucionalismo do direito, o presente artigo, objetivará reforçar o fomento de reflexões em torno dos parâmetros sustentáveis e do mínimo existencial ecológico, se utilizando, para tal intento, um acervo bibliográfico pautado no método dedutivo-qualitativo, com pesquisas de doutrinas, periódicos e demais produções acadêmicas e científicas em prol de contribuir, da melhor maneira possível, na pretensão maior em apreço, utilizando-se da modalidade revisão na sua feitura. Por derradeiro, em prol do supino robustecimento de tais conscientizações, serão abordados breves apontamentos no que tange ao direito fundamental ao meio ambiente ecologicamente equilibrado, saudável, ecodigno e respeitado em prol das presentes e futuras gerações, bem como para as demais formas de vida. Para o alcance de tal intento, é notório, por intermédio da insofismável contribuição da Educação Ambiental, que é possível ampliar-se tais diretrizes, inclusive em todos os níveis de ensino, em prol do vislumbre de alienações sendo superadas e da promoção da conscientização ambiental em torno do nosso comprometimento intergeracional.
\end{abstract}

Palavras-chave: Ecodignidade, meio ambiente, qualidade de vida, sustentabilidade.

\section{The existential ecological minimum and the salutary dictates of environmental education}

\begin{abstract}
With a preliminary emphasis on the important historical evolution of the Rule of law to the current scenario of the Democratic and Socioenvironmental State arising from the Constitutionality of law, this article fosters reflections on parameters for sustainability and the ecological existential minimum. For this purpose, we analyzed a bibliographic collection through the deductive-qualitative method, with research on doctrines, journals, and other academic and scientific resources. The study consists of a literature review aimed to contribute, in the best possible way, to greater knowledge in the area. Finally, for higher awareness on these issues, brief notes will be addressed regarding the fundamental right to an ecologically balanced, healthy, ecoworthy, and respected environment for the present and future generations, as well as for other life forms. To achieve this goal, the unquestionable contribution of Environmental Education makes it clear that it is possible to expand such guidelines at all levels of education, thus glimpsing the overcoming of alienations and the promotion of environmental awareness on intergenerational commitment.
\end{abstract}

Keywords: Ecodignity, environment, quality of life, sustainability.

\section{Introdução}

O presente artigo projeta a preocupação reiterada das autoras no que tange a atual crise paradigmática ambiental, repleta de mazelas socioecológicas que comprometem a existência planetária e, por conseguinte, de todas as formas de vida nela inseridas.

Nesse toar, tal reconhecimento, com efeito, propicia a preocupação em torno do mínimo existencial ecológico, que consiste na busca por uma ínfima possibilidade de se viver com qualidade em um ambiente dotado de dignidade e respeito para todos os seres pertencentes ao vasto sistema ecológico planetário. Se atrela também a supina importância em torno da preservação ambiental e da efetivação do direito fundamental ao meio ambiente ecologicamente equilibrado, nos moldes do artigo 225 da Constituição Verde de 1988.

Destarte, para operar tais pretensões maiores, se faz imprescindível fomentar maior conscientização voltada aos parâmetros sustentáveis. Para tal intento, a Educação Ambiental é primordial em prol de cumprir-se tais diretrizes, tendo em vista que o "educar" é propalar conhecimento, estimular mudanças, romper paradigmas, acrescer e contribuir na formação do caráter e no fomento de visões mais positivas sobre o mundo em seus plúrimos aspectos. 
Nessa linha intelectiva, o supino e inexoravelmente relevante objetivo maior da pesquisa em baila consiste em reforçar o fomento de reflexões em torno dos parâmetros sustentáveis e do mínimo existencial ecológico.

Por derradeiro, se pretende, durante a desenvoltura da pesquisa: apontar sobre a evolução histórica do Estado e as principais diretrizes do atual Estado Socioambiental de direito; analisar sobre as principais contribuições da Educação Ambiental na promoção de uma conscientização societária voltada aos parâmetros sustentáveis.

\section{O Estado democrático e socioambiental de direito no fomento do mínimo existencial ecológico}

Preliminarmente, a título de uma breve contextualização histórica no que tange ao processo evolutivo do Estado Brasileiro até o cenário hodierno marcado pela Democracia, necessário se faz algumas ponderações.

Outrora se vislumbrava a regência de uma "Constituição Feudal", a qual o Senhor Feudal era possuidor e detentor de todo o poder econômico, político, social, militar, jurídico e ideológico sobre todas as demais classes, principalmente quanto aos seus servos (Streck \& Morais, 2014).

Nesse diapasão, com a evolução social, e as revoltas dos servos, muda-se o paradigma do Feudal para um Estado absolutista, marcado pelo governo de um soberano, déspota, com poderes ilimitados. Contudo, há aqui o desenvolvimento da sociedade burguesa que passa a não concordar com o governo do soberano, manipulando então as classes sociais para tirá-lo do poder (Lassale, 2015).

Decerto que, sobrevindo tais revoltas, têm-se a queda do soberano e o surgimento de um Estado Liberal Burguês, constituindo o primeiro regime jurídico-político societário e tendo de um lado os capitalistas (burgueses em ascensão) e do outro a realeza (monarcas) bem como a nobreza (senhores feudais em decadência) (La Bradbury, 2006).

Nessa ambiência, o Estado Liberal, nos meados do século XIX, foi marcado pelo excesso de poder nas mãos burguesas e contínuas explorações aos direitos sociais, acarretando outra mudança de paradigma: O Estado Social de Direito, dentro do contexto de Pós-segunda Guerra Mundial, sendo fortemente marcado, preliminarmente, pela Constituição do México de 1917; posteriormente pela Constituição da Alemanha, de 1919; pela Constituição Espanhola de 1930; e no cenário pátrio temos esta dimensão Social a partir da Constituição Federal de 1934 (Moraes, 2018).

Com efeito, consoante às explanações de Soares (2001), o Estado Social ampliou, por sua vez, a aplicabilidade dos direitos, como da igualdade e da propriedade, exigindo-se o bem-estar social e econômico por intermédio da participação ativa da vida comunitária.

Nessa arquitetura, o Estado Social também não foi suficiente em prol de suprir as necessidades e anseios sociais, bem como respeitar os direitos individuais e coletivos, surgindo-se, nesse ínterim, a formação de um cenário democrático que buscasse um novo olhar, mais apurado, à sociedade, contemplando-se aqui os direitos chamados de "terceira geração", difusos e transindividuais.

Com a insurgência de um novo paradigma, resplandece então o Estado Democrático de direito que, sob a influência da constitucionalização do direito, irradiando seus valores essenciais para todos os demais ramos, contempla a conjuntura de um Estado Socioambiental.

Constituindo-se tal cenário, obtempera-se então o fomento de debate público, sobretudo atrelado às preocupações ambientais e, por conseguinte, existenciais, que encontra dificuldades de efetivações pelo aparente choque com o desenvolvimento nacional econômico (Barroso, 2015).

Realizada tal explanação, o desenvolvimento sustentável, tão almejado pelo hodierno Estado Socioambiental, deve ser visto como um modelo ou ideal que importa a diminuição do consumo, a promoção de investimento e a ampliação da capacidade dos indivíduos, visando-se freios às ações humanas (Cipriano, 2010), sobretudo em virtude dos recursos naturais cada vez mais explorados.

Cumpre suscitar que, nos ditames do atual Estado Socioambiental, contempla-se a formação cidadã buscando orientar o indivíduo para uma atuação política, "na medida em que resta possibilitada a contribuição para uma construção de uma coletividade atenta aos valores socioambientais." (Sorrentino, Trajber, Mendonça \& Júnior, 2005).

Nesta conjuntura, cumpre destacar que o atual Estado preocupa-se com tais valores ambientais na medida em que estes interligam-se inexoravelmente com o cunho existencial de toda a humanidade e de todas as formas de vida presentes.

Entrementes, presenciamos um contexto marcado pela notória "fragilidade de uma consciência coletiva nacional" (Buarque, 1991) embora a própria Constituição Verde de 1988 tenha previsto o supino comprometimento solidário/intergeracional de preservação ambiental como dever do Poder Público e da própria sociedade.

Pela totalidade do exposto, contudo, em virtude dessas crescentes ações antropológicas, contemplamos na realidade um cenário marcado pela deteriorização da própria qualidade ambiental (Sánchez, 2008), entendendo-se isso por “degradação da qualidade ambiental” pela ação humana (o que interessa para o direito ambiental) ou por fatores naturais (Oliveira, 2017).

Nessa sina, sendo a notória degradação ambiental "um homicídio em doses homeopáticas" (Akaoui, 2015), o direito fundamental ao meio ambiente ecologicamente equilibrado, nos moldes do artigo 225 da CF/88, e que "está intimamente ligado ao direito fundamental à vida e à proteção da dignidade da vida humana, garantindo, sobretudo, condições adequadas de qualidade de vida" (Silva, 2016), está incomensuravelmente afetado.

Ademais, tendo em vista que contemplar-se-á um "Estado de Direito Socioambiental" que obtempera a "compatibilidade axiológica entre homem e meio ambiente embaraçados em um futuro comum" (Morais \& Saraiva, 2018, p. 13), bem como a extensão e disseminação da garantia de um mínimo existencial,"que nos permitirá a seguir nosso percurso no planeta" (Molinaro, 2006), é necessário que o comprometimento solidário seja cumprido em prol do direito em baila efetivar-se. 
Logo, tamanha é a preocupação da nossa "Constituição Ambiental"- Canotilho (2007), que podemos contemplar a proteção ambiental como um dos objetivos fundamentais do Estado de Direito Ambiental brasileiro (Leite \& Belchior, 2019).

Sendo assim, a pretensão maior de conservação e proteção de um mínimo existencial ecológico combaterá gradativamente as mazelas socioambientais que fragilizam e colocam em risco "a ordem de valores e os princípios republicanos e do Estado Democrático de Direito, bem como comprometem fortemente a sobrevivência (humana e não humana) e a qualidade de vida" (Sarlet \& Fensterseifer, 2017, p. 33).

Ademais, ressalte-se a inexorável relevância do modo "como nos organizamos em sociedade, como gerimos seus instrumentos e como damos sentido às nossas vidas" (Pelacani, Muniz \& Sánchez, 2019).

Com efeito, da teoria para uma praticidade concreta, vislumbra-se que uma das mais importantes diretrizes, desse Estado Socioambiental, é o destaque e fomento da Educação Ambiental, em prol do preterido robustecimento de uma conscientização sustentável e, por conseguinte, da superação da hodierna crise socioambiental observada.

\section{Educação Ambiental e seu inexorável papel no robustecimento da conscientização socioambiental}

Compartilhando a linha intelectiva em apreço, ter-seá em análise que a "sustentabilidade não acontece mecanicamente", (Boff, 2012), obtemperando-se a "capacidade que o ser humano tem de se satisfazer no presente sem comprometer as gerações futuras", sem atingir o modelo capitalista e seu desenvolvimento econômico (Silva, Mesquita \& Souza, 2015), na medida em que é possível compatibilizálo com o desenvolvimento nos moldes sustentáveis.

Nessa moldura, atendendo-se a inevitável necessidade da busca por água e ar limpos, abrigo e outros recursos básicos para os seres vivos, pelos ditames do desenvolvimento sustentável é possível satisfazer tais necessidades sem, todavia, "comprometer a capacidade de as gerações futuras atenderem às suas necessidades" (Miller Jr, 2012, p. 5).

Por conseguinte, projetando-se aqui o viés da sustentabilidade social, ecológica, econômica, espacial, político-institucional, cultural, como bem explana Melo (2008) e Montibeller Filho (2004), notar-se-á o vislumbre da própria tutela da qualidade do meio ambiente e de todas as formas de vida nele inseridos (Silva, 1997).

De insofismável relevância se faz pertinente contemplar que tal dignidade, valor supremo da Constituição, atine hoje não apenas a vida digna como direito dos seres humanos, mas igualmente dos seres não humanos/ animais- os quais gradativamente ganham espaço no cenário hodierno no que tange ao seu reconhecimento como sujeitos de direitos. Contempla-se aqui a virtude da "ecodignidade pluralista" (Albuquerque, 2019, p. 110).

Diante de tal contexto observado, especialmente frente aos notórios "problemas de saúde e ambiente" (Freitas, 2006, p. 27), ressalte-se que a qualidade de vida depende "da qualidade do ambiente para chegar a um desenvolvimento equilibrado e sustentável (a conservação do potencial produtivo dos ecossistemas, a sustentabilidade ecológica do habitat) [...]" (Leff, 2001, p. 324).

Nos moldes da sustentabilidade e da preservação do mínimo existencial na busca pelo robustecimento da qualidade de vida e com dignidade para todos, é necessário proteger "todos os recursos naturais, incluindo todas as formas de vida existentes no planeta, ainda que se possa argumentar que tal proteção da vida em geral constitua, em última análise, exigência da vida humana e de uma vida humana com dignidade" (Sarlet, 2006, p. 34-35).

Face ao exposto, em contemplação a "faceta ecológica" (Sarmento, 2016), atinente ao nosso atual Estado Democrático e Socioambiental de Direito, é imprescindível apontar-se, a título conclusivo, sobre a insofismável contribuição da Educação Ambiental, a qual visa o fomento de tais parâmetros sustentáveis na esperança maior de uma conscientização societária em torno da crise socioambiental que compromete a existência ecológica.

Nessa ordem de ideias, ressalte-se que o Brasil "é o único país da América Latina que possui uma política nacional específica para a Educação Ambiental" (Bortolon \& Mendes, 2014, p. 128).

Malgrado tal observância, saliente-se que outros países, igualmente preocupados com as questões ecológicas, possuem o amparo legislativo no que tange ao "direito á natureza", a exemplo do exemplar artigo 34 da Constituição da Bolívia, o qual "também garante ampla proteção jurídica à Natureza, admitindo que qualquer pessoa individual ou coletiva possa defender os direitos de um rio ou uma bacia hidrográfica, por exemplo, perante o Poder Judiciário" (Caletti \& Staffen, 2019, p. 290).

Tal cenário projeta uma mudança de paradigmas necessária em prol de uma releitura frente à evolução histórica dos primeiros direitos fundamentais, os adaptando a uma nova demanda social (Maulaz, 2010), que busca por qualidade de vida, equilíbrio ambiental, ambiente propício, saudável e digno em prol de abarcar as presentes e futuras gerações, bem como todas as demais formas de vida.

Assim sendo, deve-se limitar a notória "potencialização da exploração humana da natureza pela técnica civil da moderna sociedade industrial em seu conjunto" (Apel, 1994, p. 166). Para tal intento, o ordenamento pátrio prevê, a título exemplar, a Responsabilidade Socioambiental Objetiva, precipuamente "voltada à preservação e ao controle de riscos sociais e ambientais" (Dias \& Messias, 2019, p. 244), na medida em que "toda crise ambiental é essencialmente uma crise paradigmática" (Filho, 2015, p. 96).

Ademais, apesar de tal diretriz maior, contemplamos na realidade planetária, mas especialmente em alguns países como o Brasil, alguns problemas enfrentados pelos educadores, nos mais variados níveis de ensino, na promoção da educação ambiental.

Exemplificando, notar-se-á frente a tal realidade: a "sobrecarga horária, turmas superlotadas, e indisciplinas". Em que pese tais casos, é possível ainda estimular os parâmetros educacionais sustentáveis "por meio da aplicação de diferentes tipos de atividades lúdicas que estimulem a 
curiosidade e a criatividade dos alunos", possibilitando ao estudante/discente "não apenas ficar limitado ao espaço da sala de aula, mas também interagir e, quem sabe, reconstruir aspectos da dinâmica do ambiente escolar e da própria comunidade" (Aguiar, 2017, p. 111).

Nesse ínterim, as diretrizes mais salutares contempladas mais precisamente na Educação Ecológica, embora outros doutrinadores a considerem também sob a ótica da Educação Ambiental (a exemplo de Guerra, 2019), são a busca pela ampliação do conhecimento aos parâmetros sustentáveis, objetivando a qualidade de vida, repleta de dignidade, saúde e respeito para todos. Tais ditames projetam a própria essência da chamada "Ecopedagogia" (Guerra, 2019).

Sendo assim, com os ditames pregados pela Educação Ambiental, é possível ampliar-se o que mais é escasso hodiernamente: a conscientização ambiental, voltada aos parâmetros sustentáveis, a mudanças de hábitos e ao vislumbre de um efetivo desenvolvimento sustentável voltado a proteção do mínimo existencial ecológico (Ferreira et al., 2019).

Nesses moldes, visando igualmente à promoção de "medidas verdes", se faz essencial "à criação de condições para a realização de pesquisas destinadas a redirecionar a ampliação do conhecimento científico e o desenvolvimento de opções tecnológicas" (Clóvis, 2002, p. 83). Para contemplarse tal diretriz, é necessário o comprometimento do Poder Público em prol de possibilitar tais pesquisas.

Dessa forma, investindo-se em educação, gerar-se-á reflexos positivos e incomensuráveis para todos, pois uma sociedade alienada favorece o retrocesso socioambiental por intermédio de suas condutas prejudiciais e exacerbadas, tanto no que tange ao consumo extremo, quanto no que se refere a falta de conscientização ecológica.

Tal reconhecimento possibilita que a educação ambiental propicie, por conseguinte, "considerável amplitude de argumentos, posicionamentos teórico-metodológicos e apropriações de conceitos das mais variadas ciências e projetos societários." (Araújo, Santos \& Silva, 2012).

Com a ruptura gradativa de tais alienações, é possível vislumbrar-se um real meio ambiente dotado de qualidade de vida, saúde, dignidade e respeito como meta primordial de realização da espécie humana em equilíbrio com a natureza (Milaré, 2018).

Nessa conjuntura, a conscientização (promovida pela educação ambiental) em baila promoverá uma sociedade mais sustentável, comprometida com as gerações presentes e vindouras, que apenas colherá frutos inexoravelmente positivos em virtude do apreço ao mínimo existencial ecológico.

Na linha intelectiva ora construída, tendo em vista as diretrizes pertinentes da Educação Ambiental, é importante destacar que é uma incumbência intergeracional de cada cidadão buscar pela efetivação de tais nuances.

$\mathrm{Na}$ linha intelectiva construída, observar-se-á que, investindo em educação, nos mais variados níveis de ensino, possível será então o vislumbre de um ambiente efetivamente respeitado, dotado de ecodignidade, saúde e qualidade de vida, propício a contemplar as gerações presentes e futuras.
Em face do exposto, a presente pesquisa buscou contribuir, mesmo que infimamente, no fomento de reflexões necessárias em face das diretrizes da educação ambiental em prol da ruptura de alienações, superação de mazelas socioambientais, e o devido respeito ao mínimo existencial ecológico na contemplação de todas as formas de vida deste vasto sistema planetário.

Tais ditames se mostram imprescindíveis na conjuntura hodierna, sobretudo tendo em vista os mais atuais acontecimentos atrelados às queimadas na Amazônia, e o problema dos vazamentos de óleos nas praias nordestinas. Tais mazelas ambientais trazem impactos maléficos para os seres humanos e não humanos, prejudicando a saúde, o ambiente natural e a derradeira qualidade de vida para todos. Sendo assim, necessárias mudanças se fazem pertinentes, por intermédio de atuações do Poder Público e da coletividade, para uma melhoria de paradigma em prol do mínimo existencial ecológico.

\section{Referências}

Aguiar, P., Costa Neto, R., Bruno, N., \& Profice, C(2017). Da teoria à prática em educação ambiental. Revista gestão e sustentabilidade ambiental, 6(2), 111-132. doi: 10.19177/rgsa.v6e22017111-132.

Akaoui, F. R. V. (2015). Compromisso de ajustamento de conduta ambiental. São Paulo: editora revista dos tribunais.

Albuquerque, A. A. U. L. (2019). Princípio constitucional da ecodignidade pluralista: breve introdução aos caracteres do processo de etnodemocratização. Revista direitos fundamentais \& Democracia, 24(1), 91-125. doi:10.25192/issn.1982-0496.rdfd.v24i11427

Apel, K. O. (1994). Estudos de moral moderna. Tradução benno dischinger. Petrópolis: vozes.

Araújo, N. M. S., Santos, J. S, \& Silva, M. G. (2012). Educação ambiental e serviço social: o peac e o licenciamento na gestão pública do meio ambiente. São cristóvão: editora UFS.

Barroso, L. R. (2015). Curso de direito constitucional contemporâneo (8a ed.). São Paulo: Saraiva.

Boff, L. (2012). Sustentabilidade: o que é, o que não é? Petrópolis: vozes.

Bortolon, B., \& mendes, M. S. S. (2014). A importância da educação ambiental para o alcance da sustentabilidade. Revista eletrônica de iniciação científica, 5(1), 118-136.

Booth, W. C, Colomb, G. G., \& Williams, J. M(2000). A arte da pesquisa. Tradução de henrique a. Rego monteiro. São paulo: Martins Fomes.

Buarque, C. (1991). O colapso da modernidade brasileira e uma proposta alternativa: com a colaboração de Aldo paviani \& Cristovam Buarque. Rio de Janeiro: paz e terra.

Caletti, L., \& Staffen, M. R(2019). A fragmentação jurídica e o direito ambiental global. Revista veredas do direito: direito ambiental e desenvolvimento sustentável, 16(34), 279-310. doi: 10.18623/rvd.v16i34.1455.

Canotilho, J. J. G. (2007). Direito constitucional ambiental português e da união europeia. In: canotilho, josé joaquim gomes; morato leite, josé rubens (orgs.). Direito constitucional ambiental brasileiro. São Paulo: Saraiva.

Cipriano, T. A. R. P. (2010). O conceito econômico-jurídico de desenvolvimento sustentável. Texto vencedor do prêmio José Bonifácio de Andrada e Silva, promovido pelo instituto o direito por um planeta verde, São Paulo.

Clóvis, E(org.). (2002). Meio ambiente, desenvolvimento sustentável e políticas públicas. São Paulo: Cortez: Recife: Fundação Joaquim Nabuco.

Dias, J. A. D., \& Messias, E. R. (2019). Responsabilidade civil contratual e extracontratual frente à responsabilidade civil ambiental: uma análise sob o direito pós-moderno. Revista direitos fundamentais e democracia, 24(1), 243-265, Recuperado de 
http://revistaeletronicardfd.unibrasil.com.br/index.php/rdfd/article/view/ $1276 / 577$

Eco, U. (2008). Como se faz uma tese. Tradução gilson cesar cardoso de souza. 21. Ed. São paulo: perspectiva, 2008.

Ferreira, L. C., Martins, L. C. F., Merotto, S. C., Raggi, D. G., \& Silva, J. G. $\mathrm{F}(2019)$. Educação ambiental e sustentabilidade na prática escolar. Revista brasileira de educação ambiental- revbea, 14(2), 201-214. doi: 10.34024/revbea.2019.v14.2678

Filho, A. A. S. (2015). Crise ambiental moderna: um diagnóstico interdisciplinar. Porto alegre: Redes editora.

Freitas, E. M. (2006). Saúde, ambiente e sustentabilidade. Rio de janeiro: editora Fiocruz.

Guerra, f. S. (2019). Ecopedagogia: contribuições para práticas pedagógicas em educação ambiental. Ambiente \& educação, revista de educação ambiental programa de pós-graduação em educação ambiental universidade federal do rio grande. 24(1), 235-256. doi:10.14295/ambeduc.v24i1.8027

La bradbury, L. C. S. (2006). Estados liberal, social e democrático de direito: noções, afinidades e fundamentos. Revista jus navigandi. 11(1252).

Lassale, F. (2015). O que é uma constituição. São paulo: Pillares.

Leff, E. (2001). Saber ambiental: sustentabilidade, racionalidade, complexidade, poder(4a ed.). Tradução: lúcia mathilde endlich orth. Petrópolis: Vozes.

Leite, J. R. M., \& belchior, G. P. N. (2019). Direito constitucional ambiental. In: trennepohl, t. F. T(coord). (2019). Direito ambiental brasileiro. São Paulo: Thomson Reuters Brasil.

Marconi, M,. \& Lakatos, E. (2009). Metodologia científica. São Paulo, atlas.

Maulaz, R. B. (2010). Os paradigmas do estado de direito. O estado liberal, o estado social (socialista) e o estado democrático de direito. Revista jus navigandi. 15(2628).

Melo, J. M. (org.). (2008). Mídia, ecologia e sociedade. Prólogo dov shinar; autores: bernardo diaz nosty, et al. São Paulo: Intercom.

Milaré. E(2018). Direito do ambiente(4a ed.). São Paulo: Thomson Reuters Brasil.

Miller JR., G. T(2012). Ciência ambiental. Tradução: all tasks; revisão técnica welington braz carvalho delitti (11a ed. norte americana). São Paulo: Cengage Learning.

Molinaro, C. A. (2006). Racionalidade ecológica e estado socioambiental e democrático de direito. Dissertação de mestrado. Programa de pósgraduação em direito da faculdade de direito da pontifícia universidade católica. Porto Aegre, PR.

Montibeller Filho, G. (2004). Meio ambiente e custos sociais no moderno sistema produtor de mercadorias. Florianópolis: Editora UFSC.

Moraes, G. P. (2018). Curso de direito constitucional. São Paulo: Atlas.

Morais, J. L. B., \& Saraiva, B. C. (2018). O estado de direito socio-ambiental como condição de possibilidade destinada à tutela do futuro. Revista veredas do direito: direito ambiental e desenvolvimento sustentável, 15(32), 11-37. doi: 10.18623/rvd.v15i32.1159

Oliveira, F. M. G(2017). Direito ambiental(2a ed.). Rio de Janeiro: Forense; São Paulo: Método.

Pelacani, B., Muniz, T. S. A., \& Sánchez, C. (2019). Educação ambiental crítica e estudos de patrimônio crítico:intersecções e virada para pedagogias decoloniais. Revista brasileira de educação ambientalrevbea. 14(2), 133-151. https://doi.org/10.34024/revbea.2019.v14.2632

Pessoa, F. M. G. (2009). Manual de metodologia do trabalho científico: como fazer uma pesquisa de direito comparado. Aracaju: Evocati.

Richardson, R. J. (1999). Pesquisa social: métodos e técnicas. Colaboradores José Augusto de Souza Peres (et al). São Paulo: Atlas.

Sánchez, L. E. (2008). Avaliação de impacto ambiental: conceitos e métodos. São Paulo: Oficina de Textos.

Sarlet, I. W. (2006). Dignidade da pessoa humana e direitos fundamentais na constituição federal de 1988. (4a ed.). Porto Alegre: Livraria do Advogado.

Sarlet, I. W., Fensterseifer, T(2017). Direito constitucional ambiental(3a ed.). São paulo: Revista dos Tribunais.

Sarmento, D. (2016). Dignidade da pessoa humana: conteúdo, trajetórias e metodologia. Belo Horizonte: Fórum.
Silva, J. A. (1997). Direito ambiental constitucional(2a ed.). São Paulo: Malheiros.

Silva, R. F. T. (2016). Direito ambiental(6a ed.). Salvador: Juspodivm.

Silva, A. C., mesquita, G. M., \& Souza, M. A. P. (2015). Educação ambiental como paradigma para a construção da sustentabilidade. Revista eletrônica em gestão, educação e tecnologia ambiental santa maria. 19(2), 1133-1140.

Soares, M. L. Q. (2001). Teoria do estado: o substrato clássico e os novos paradigmas como pré-compreensão para o direito constitucional. Belo Horizonte: Del Rey.

Sorrentino, M., Trajber, R., Mendonça, P., \& Junior, L. A. F. (2005). Educação ambiental como política pública. Educação e pesquisa, 31(2), 285-299.

Streck, L. L \& Morais, J. L. B. (2014). Ciência política e teoria do estado(8a ed.). Porto Alegre: Livraria do Advogado.

\section{Licença Creative Commons CC BY 4.0}

Este artigo foi publicado com acesso aberto para distribuíção sob os termos do Licença de Atribuição Creative Commons, que permite uso irrestrito, distribuição, e reprodução em qualquer meio, desde que o trabalho original seja devidamente citado. 